\title{
Circles of Support and Accountability: An Innovative Approach to Manage High-Risk Sex Offenders in the Community
}

\author{
Chris Wilson ${ }^{1}$, Andrew Bates ${ }^{2}$ and Birgit Völlm*,3 \\ ${ }^{I}$ Circles UK, Reading, UK; ${ }^{2}$ Thames Valley Probation Service, Bicester, UK; ${ }^{3}$ Section of Forensic Psychiatry, Division \\ of Psychiatry, University of Nottingham, UK
}

\begin{abstract}
Sex offenders cause particular concern upon release and are often received with apprehension or hostility by the community. This in turn may increase their feelings of loneliness and poor self-esteem hindering re-integration and potentially increasing re-offending. Circles of Support and Accountability (CoSAs) were first developed in Canada in 1994 and introduced in the UK in 2000. A "Circle" consists of a group of four to six volunteers with the offender as the "Core Member". Appropriately trained volunteers support and hold to account the core member, who has to volunteer to be part of the scheme, by providing them with social contact and practical support while at the same time maintaining links to statutory agencies alerting them of any risk issues. Following completion of initial pilots the scheme is currently rolled out across the UK. This systematic review will describe the Circles model and its history and summarise the empirical literature particularly with regards to outcomes.
\end{abstract}

Keywords: Sex offender, Circles, community, reintegration.

\section{INTRODUCTION}

A Circle of Support and Accountability (a Circle) is a group of trained volunteers who meet on a regular basis both as a group and as individuals with a high risk sex offender (core member) living in their community. They hold him or her accountable for past offending behaviour through a relationship of care and support. This relationship seeks to enhance any treatment plan the core member may have prepared and helps to formulate personal goals which will hopefully result in the attainment of a more satisfying and fulfilling life. The Circle is supervised by a professionally qualified (e.g. probation officer, social worker, etc.) coordinator who also acts as a conduit for all relevant communication and information between the Circle and those statutory agencies responsible for the core member's risk management.

\section{Development of Circles in Canada}

Circles of Support and Accountability (Circles) developed in Canada as a positive response to a specific incident of public fear and outrage (Hamilton, Ontario 1994) at the release from prison of a high-profile child sex offender into their community. The Mennonite faith community, worried by the demonising of this particular individual and the moral panic he engendered, responded with a restorative-justice based concept and established the first Circle of Support and Accountability. In the same year, a similar situation occurred in Toronto and another Circle was formed for a released high-risk sex offender.

In 1996 the Mennonite Central Committee in Ontario produced a manual for the delivery of Circles and entered

*Address correspondence to this author at the Section of Forensic Psychiatry, Division of Psychiatry, University of Nottingham, UK;

Tel: 0115 8231299; Fax: 0115 8231263;

E-mail: birgit.vollm@nottingham.ac.uk into a contract with Correctional Services Canada who saw this as an opportunity for communities to play a positive role in enhancing public protection. Likewise, those Police Officers who had experience of Circles also began to realise that Circles could be seen as a part-solution to the scarce resources available to them and enhance their ability to effectively manage high risk sex offenders. Sex offender treatment providers were also accepting that Circles of Support and Accountability were not in any way at odds with the work of community-based treatment programmes, but were likely to enhance them.

Since its initial inception, Circles have been established at 18 different sites, supporting 150 sex offenders in the community, in Canada. In November 2009 the Canadian government had agreed to further funding of $\$ 7.4$ million over 5 years for Circles of Support and Accountability thereby demonstrating their ongoing commitment to the scheme.

\section{Establishment of Circles in the UK}

Since the Mennonite Church established their first Circle in 1994, Circles of Support and Accountability has become one of the best known 'restorative based reintegrative schemes for sex offenders' (McAlinden, 2007). Circles in Canada were initially conceived as a community reintegration project based on restorative principles. This was a concept that the Mennonites had been championing since the early 1970s. Quakers are another faith group with a long history of engaging in work in prison and crime prevention using humane and innovative approaches. The Crime and Community Justice Committee of the Quakers in Britain became aware of Circles projects in the UK and approached the Home Office Dangerous Offenders Unit which agreed to set up a workshop to explore the scheme and subsequently 
invited two probation areas to consider setting up Circles projects. These initial pilot projects received government funding and were managed by Quaker Peace and Social Witness, a central Quaker body in the UK. It is of significance that one of the pilots was located in Thames Valley Police, a Probation area which already had an excellent record in restorative practice, and both agencies were active partners in the project's development and sustainability. Such was the success of this project that it launched as an independent Charity known as HTV Circles in 2008 and its theoretical frame work for the delivery of Circles has been used in the development of subsequent projects across the United Kingdom, Belgium and Holland. This theoretical framework gave Circles the ability to develop within a context of risk management irrespective of differing faiths and beliefs.

Thames Valley Circles of Support and Accountability was established in 2002, along with two other pilot projects. The Hampshire project lasted two years before it combined with the Thames Valley pilot in 2005 while a child protection charity, the Lucy Faithfull Foundation, provided the third pilot site. The Foundation provided the only residential sex offender treatment programme in the country and had successfully set up a Circle prior to government funding. They continued with a national remit, initially creating Circles for ex-residents who had completed treatment and were relocated across the country.

It was a brave decision by the British government to fund three pilot Circle projects for a period of three years, particularly against a backdrop of public hysteria and moral panic over child sex offenders. Although, to some, Circles was and remains a politically contentious project, its underlying philosophy of community responsibility sits firmly within the government's Criminal Justice and Civil Renewal agendas as exampled by the "Volunteers Can. A Volunteering Strategy to Reduce Re-offending'; May 2007, http://www.noms.homeoffice.gov.uk/news-publicationsevents/publications/consultations/Consultation_Volunteers _ $\mathrm{Can} /$ ). It must also be remembered that Circles were initially funded by the government at a time when both the policy and practice framework for the management of sex offenders living in the community was under reorganisation with the then newly created National Offender Management Service (NOMS; http://www.justice.gov.uk/about/noms.htm). This was to be a reorganisation that brought together the Prison and Probation Service into one organisation and devolved budgets into regional areas. The restorative aim of Circles to achieve accountability through a relationship of support and inclusion was wholly consistent with the core values of NOMS. This model of offender management was based upon a personal relationship rather than a bureaucratic one, and that this relationship was to be one in which the offender takes an active part. One of the core values of NOMS is 'involvement of local community in offender management through improving communication with local people, fostering greater organisational awareness of public concerns and encouraging active participation of the community in local projects' It is not unreasonable to believe that these values could result in Circles becoming an integral part of offender management specific to those sexual offenders who would benefit from Circles.

\section{The Theoretical Framework}

The development of Circles in the UK required a specific theoretical framework that would address both the differing legal and cultural context between Canada and Britain. It would have been naive not to recognise the contextual differences. For example, in Canada Circles were needed specifically for those offenders assessed as high-risk based on standard risk assessment tools. Such an assessment results in the offender serving the whole of their sentence and being released without parole or supervision in the Canadian system. In England and Wales there had been over a decade of legislation related to sexual offending, designed not only to enhance the effective management of high-risk sex offenders but also to assuage public anxiety. Canadian Circles were truly organic in their development. Originally rooted within the Mennonite faith community, they responded in a positive and inclusive manner to a wider community fear. While this philosophy was shared by those seeking to establish Circles in Britain, the systems of managing sex offenders released from prison in Britain was very different from that of Canada; therefore the way in which Circles were implemented in England was the antithesis of that in Canada. Circles in Canada grew out of the community in a spontaneous and organic manner, while in Britain Circles developed systemically, funded and therefore, to a degree, controlled by government. Having acknowledged the differences it is important to recognise that it is their similarities, the principles of inclusion and restoration through positive human relationships, which have been the hallmark of their growth both in Canada and Britain.

The theoretical framework that was to underpin the process of all Circles work in Britain was based on three key principles; Support, Monitor and Maintenance (Saunders \& Wilson, 2003) with the intention to address those issues that were significant to the recidivism of sexually aggressive behaviour. Each principle contains within it a number of key issues relating to the desistance of sexual offending and thereby the enhancement of public protection. The principle of Support begins with the acknowledgment that research had evidenced isolation and emotional loneliness as significant factors in recidivist behaviour (Hanson \& MortonBourgon, 2005). It is also accepted that deficits in offenders perceptions of intimacy and the failings in attachments demonstrate the need for appropriate adult modelling. Such modelling is a central feature of the volunteer's role. However, real change can only be attained through a relationship of mutual respect and regard. The catalyst for change, within a context of sex offender treatment, has been identified as dependent upon the collaboration between therapist and offender in the development of treatment objectives and goals. This collaboration results in a stronger therapeutic alliance (Wilson, Picheca \& Prinzo, 2007a). The continued support offered by a Circle in helping the core members pursuit of an offence free life must also be offered within a context of mutual regard. Any relationship is only meaningful if it is based on honesty and trust. The Circle needs to continue modelling those alliances and work to develop the offender's strategies to avoid re-offending previously identified through treatment. It is in this way that the Core Member can acquire the mechanisms needed to achieve a positive life. The Core member is only likely to accept the duality of support with 
accountability if it is delivered within a context of humanity and care.

The second principle of Monitoring is built upon the ability of Circles to place themselves within the existing structure of inter-agency cooperation. Never more so is the duality of support and accountability exemplified as in its role within the Multi Agency Public Protection Arrangements (MAPPA). This is the statutory structure that has a strategic responsibility for the oversight of agencies responsible for the management of sexual and violent offenders living in the community. MAPPA bring these agencies together on a regular basis to review, discuss, and formulate action plans. By definition MAPPA's process and actions tend to be reactive methods of control such as registration, sex offender prevention orders and community notification. Circles afford this process the ability to gain intelligence, for the purposes of public protection, through a creative and community based initiative. This model of communication does not seem to inhibit the relationship between the Core Member and his or her volunteers; particularly if volunteers are clear in articulating the need to keep all concerned stakeholders informed. There is growing evidence accrued from practice that Core Members continue to share problematic behaviours with their Circle volunteers, knowing that any information relating to child or public protection will be communicated through the MAPPA process. The fact that they are prepared to disclose information to the volunteers is evidence as to the viability of positive community involvement relating to public protection. As such, monitoring becomes a positive and community based activity.

The third key principle, Maintenance, is specifically linked to the relationship between sex offender treatment and Circles and their combined role in the prevention of reoffending. Many high risk sexual offenders are socially isolated and without a support network other than those key professionals, paid to be in their lives. The better lives/new life plan (formally know as a relapse prevention plan), detailing re-offending prevention strategies, needs to be shared with significant others. The purpose of a Circle, in its purest form, is to provide the Core Member with a support network so that the offender's attempts to sustain a balanced, selfdetermined lifestyle become meaningful as defined by the Good Lives Model (Ward \& Gannon, 2006). In this way the Circle can help to hold the Core Member accountable, maintaining treatment objectives as well as the expectations of the community.

Circles are provided on a voluntary basis to offenders; therefore they will, e.g., not be part of the release conditions. Other interventions may be provided alongside Circles and participation or otherwise of offenders in Circles does not affect access to these.

\section{How Does a Circle Work in Practice?}

Those offenders wishing to be part of a Circle do so out of a desire to desist from re-offending. After a referral to a project has been made either by the offender themselves or by their offenders manager, their motivation and the reasons that belie that motivation is explored by a Circles Coordinator during a process of assessment relating to their suitability for inclusion. The motivation for an offender to be included in a Circle can span a continuum ranging from a realisation and acceptance of harm caused by their previous offending to a straight forward desire not to return to prison. Given that a Circle relies on volunteers to operate, resources are finite and therefore a waiting system for allocation is crucial. It is also important to remember that Circles of Support and Accountability were set up to work with offenders who pose a significant risk of future sexual harm to the public. In a recent, as yet unpublished, study of Hampshire and Thames Valley Circles out of a total $60 \mathrm{CMs}$ receiving the intervention $13 \%$ were identified as at Very High Risk of sexual reconviction using Risk Matrix 2000, 23\% were High Risk and $28 \%$ Medium Risk. These scores do not take into account risk of harm estimates from prison and probation OaSYS assessments. All Circles volunteers and Core members sign a Circles agreement that defines the boundaries of confidentiality and what information is shared and when. Circles Coordinators and volunteers operate within a framework defined by the Circles policy and procedures document distributed by the Circles umbrella organization, Circles UK.

Once a volunteer has been successfully screened (interviews, references and enhanced criminal records check) and trained they will meet their fellow Circle volunteers and undertake a further month training in their Circle before meeting the Core member. When the Core member joins his/her Circle, the Circle will then meet on a regular weekly basis where the Core member will share the work he or she has undertaken in treatment. The specific purpose of this is so that the volunteers will not only learn to recognise when the Core member is falling into old patterns of behaviour but will be aware of the Core member's coping strategies. When the Circle and the Circle coordinator feel all are ready, weekly individual contact with the Core member will take place, engaging in safe activities that will hopefully enhance the Core member's life. This allows the Circle to facilitate the better life/new life/relapse prevention plan to become truly dynamic, whereby the Core member's coping strategies to avoid re-offending can be supported by others. The first 12 to 24 months of a Circle will be structured and monitored through its regular weekly business meetings and individual volunteer contact with the Core member all of which is recorded and when necessary fed back to the relevant agencies. This period of a Circle's life is known as phase one. Phase two is when formal supervision by the Coordinator comes to an end and volunteers continue to support the Core member on a more informal basis, i.e. the Circle may only meet as a whole for specific or special occasions but individual contact continues with volunteers reporting any significant changes in a Core member's lifestyle that may influence contextual risk. It is the development of phase two that has proved to be of a major benefit to the Police. The Police are funding five of the ten operational Circles projects across England and Wales. Phase two Circles provide the police with intelligence and information on registered sex offenders long after licence conditions have ended and other statutory agencies have ceased to be involved. While the objective of a Circle is to help facilitate the Core member's successful reintegration back into the community and not to make the Core member Circle dependent, many of the volunteers will continue an appropriate supportive relationship with their Core member long after the Circle formally closed.

As previously stated the three key principles provide foundations through which volunteers, acting as representa- 
tives of their community, can effectively hold an offender accountable through a relationship of support. Volunteers are the essential ingredients to the success of any Circles project. It is therefore vital that volunteers too are supported, monitored, and held accountable for the work they are undertaking. This supervision needs to be undertaken by a coordinator who not only understands the issues related to risk management, but who also understands the needs of the volunteers. The Circles coordinator provides this guidance and advice both formally and informally. The personal well being of volunteers is paramount and, as such, they are invited to attend quarterly reviews in which they can explore their experience of Circles work.

As in the original Canadian model, the experience of volunteers working in Circles in Britain is built upon a foundation of training. Volunteering for Circles can be far more demanding than other types of volunteer work. After an initial interview, designed to elicit motivation, attitudes and beliefs, the prospective volunteers are invited to an introductory training programme lasting 16 hours. They are screened and assessed for suitability. After further training within the Circle prior to meeting their Core Member, it is hoped that volunteers will be familiar with the model and the expectations placed upon them to be able to function as effective volunteers. The aim is to ensure that each Circle has a balance of gender, age, experience and skills, reflecting a true representation of community. This ensures both a healthy robustness to the Circle and that the needs of the Core member can be addressed and managed by the volunteers. A series of further training events is made available to the volunteers throughout the year, which include housing and employment issues, substance misuse, questioning styles, and listening skills.

\section{Circles UK}

The growth of Circles in England and Wales since 2002 has been so significant, with ten operational projects, and more in development, that the government recognised the need to support and fund a new charitable organisation known as Circles UK. This was to be an umbrella organisation to ensure that the best practice developed during the pilot period was disseminated and adhered to. Circles UK was launched in 2008.

With six key tasks, the organisation has been charged to:

- ensure the development and delivery of Circles of Support and Accountability,

- ensure the quality and consistency of practices through training and assessment processes,

- coordinate a national perspective for the evaluation and research of Circles,

- promote an awareness and provide consistent, accurate information about Circles,

- maintain the profile of Circles activity with strategic partners at national and regional level, and

- ensure the sustainability of local Circles project and to support their expansion into mainstream activity by adopting a coordinated and high level approach to funding negotiations.
While fulfilling the tasks listed above, Circles UK has also entered into a partnership of consultation, training and research has been developed between Circles UK, the Dutch University of Applied Sciences Avans Hogeschool and the Dutch and Belgium Probation departments which has now secured European funding (Daphe 3) for research into the effectiveness of Circles in reducing further sexual offending.

Circles UK has during its first year of operation developed a Code of Practice both for the governance of Circles projects and to ensure a standard of best practice regarding the operational delivery of Circles. A structure has been created that will monitor and evaluate the future service delivery of projects measured against the Code of Practice. Circles UK has built upon and ensured consistency in the delivery of both the initial volunteer training and subsequent on-going volunteer training. It has developed and delivers a national coordinators training programme as well as facilitating regular forums for coordinators to share practice, etc. It has commissioned a fund raising protocol so that projects are not all chasing the same pot of money from those charities and trust willing to support the work of Circles.

\section{LITERATURE REVIEW OF EMPIRICAL STUDIES}

This review aims to systematically and critically evaluate the empirical literature relevant to Circles focusing on studies on the impact of this concept on outcomes for sex offenders, volunteers, professionals and the wider community.

\section{Method}

We identified studies investigating the effect of Circles on outcomes in sex offenders or their impact on volunteers or other stakeholders using searches up to October 2009. We included the databases Medline, Embase, PsychInfo, ASSIA, IBSS, Sociological Abstracts and LexisLibrary. Reference lists of identified papers were checked. In addition, a Google search was conducted for any grey literature. Search terms included "Circle(s)" and "sex offender" or "sex offence".

\section{Results}

\section{Studies Identified}

19 papers with a primary focus on Circles were identified. The majority described the concept or the development of Circles while only four papers reported on empirical studies. These contributions are summarised in Table 1. We also identified some grey literature, namely two relevant evaluation reports reporting empirical data which are also listed in Table 1.

\section{Core Members' Views on Circles}

Three of the studies identified reported on the views of Core Members (CMs) on Circles (Cesaroni, 2001; Haslewood-Pócsik, Smith \& Spencer, 2008; Wilson, Picheca, \& Prinzo, 2007a). The main motivation for CMs to join a Circle was to receive emotional and practical support following release from prison. Interestingly, even though Circles operate on a voluntary basis, a high proportion (up to $30 \%$ in Canadian Circles) felt under pressure to agree to become a $\mathrm{CM}$ and feared negative consequences from the statutory agencies if they didn't. Canadian CMs reported 
Table 1. Empirical studies on Circles of Support and Accountability

\begin{tabular}{|c|c|c|c|c|c|}
\hline Author, Year & Type of Study & Setting & Groups Studied & $\begin{array}{l}\text { Methods and } \\
\text { Outcomes }\end{array}$ & Findings \\
\hline Cesaroni, 2001 & $\begin{array}{l}\text { Survey of CMs, } \\
\text { volunteers, } \\
\text { Circles } \\
\text { professionals } \\
\text { and other } \\
\text { professionals }\end{array}$ & $\begin{array}{l}\text { Mennonite } \\
\text { Circles, } \\
\text { Canada }\end{array}$ & $\begin{array}{c}12 \text { core members } \\
\text { (CMs; out of } 13 \\
\text { approached): } 9 \text { in } \\
\text { active Circles, } 3 \text { in } \\
\text { informal (later } \\
\text { stages) Circles } \\
45 \text { volunteers (out of } \\
\text { potential } 53 \text { ) }\end{array}$ & $\begin{array}{l}\text { In person }(\mathrm{CM}) \text { or } \\
\text { phone (volunteers) } \\
\text { interviews }\end{array}$ & $\begin{array}{l}\text { Core members: } \\
\text { - } \quad \text { Motivation: self-protection, isolation, "last } \\
\text { resort", perceived pressure } \\
\text { - } \quad \text { Half felt they would have re-offended with- } \\
\text { out the Circle, one quarter that they would } \\
\text { have returned to drugs and criminal lifestyle } \\
\text { - } \quad \text { Other benefits: practical matters, emotional } \\
\text { support, learning to socialise } \\
\text { Volunteers: } \\
\text { - } \quad \text { Motivation: empathy, personal experience } \\
\text { with abuse, relevant skills, perceived bene- } \\
\text { fits to community, reintegration of offender } \\
\text { Perceived benefits: practical and emotional } \\
\text { help with reintegration }\end{array}$ \\
\hline $\begin{array}{l}\text { Wilson et al., } \\
2005 \\
\text { (subsequently } \\
\text { published in } \\
\text { Wilson } \text { et al., } \\
\text { 2007a) }\end{array}$ & $\begin{array}{l}\text { Survey of CM, } \\
\text { volunteers, } \\
\text { Circles } \\
\text { professionals, } \\
\text { members of } \\
\text { community }\end{array}$ & $\begin{array}{c}\text { Canadian } \\
\text { Circles }\end{array}$ & $\begin{array}{c}24 \text { core members } \\
\text { (out of } 37 \text { ) } \\
57 \text { volunteers (out of } \\
84 \text { ) } \\
16 \text { Circles } \\
\text { professionals (out of } \\
20 \text { ) } \\
77 \text { members of } \\
\text { community (out of } \\
176 \text { ) }\end{array}$ & $\begin{array}{l}\text { Questionnaires, } \\
\text { completed in writing }\end{array}$ & $\begin{array}{l}\text { Core members: } \\
\text { Motivation: social support, reintegration, } \\
\text { negative community response, pressure to } \\
\text { become involved } \\
\text { - } \quad \text { Benefits: reintegration, practical issues, } \\
\text { opportunity to socialise, support and accep- } \\
\text { tance } \\
\text { - Majority felt Circles had helped them adjust } \\
\text { and prevented them from re-offending } \\
\text { Volunteers: } \\
\text { - Motivation: wanting to give something } \\
\text { back, personal experience with sexual of- } \\
\text { fending, excitement } \\
\text { Experience: increased confidence, friend- } \\
\text { ship, making a difference, sense of commu- } \\
\text { nity, somewhat more critical comments } \\
\text { over time } \\
\text { Majority felt CM would have offended } \\
\text { without Circle and that community felt safer } \\
\text { Professionals: } \\
\text { Felt volunteers needed more support, posi- } \\
\text { tive impact on CM: responsibility, account- } \\
\text { ability, support, increased sense of safety } \\
\text { for community, concerned about lack of } \\
\text { structure/boundaries } \\
\text { Community members: } \\
\text { 70\% positive about project, only few angry } \\
\text { about support for offenders, increased sense } \\
\text { of safety }\end{array}$ \\
\hline $\begin{array}{l}\text { Wilson et al., } \\
2005 \\
\text { (subsequently } \\
\text { published in } \\
\text { Wilson } \text { et al., } \\
\text { 2007b) }\end{array}$ & $\begin{array}{c}\text { Controlled trial } \\
\text { with matched } \\
\text { control group, } \\
\text { not randomised }\end{array}$ & $\begin{array}{c}\text { Canadian } \\
\text { Circles }\end{array}$ & $\begin{array}{l}60 \text { Core Members, } \\
\text { high risk } \\
60 \text { controls matched } \\
\text { on risk, time in } \\
\text { community and } \\
\text { treatment history }\end{array}$ & $\begin{array}{l}\text { Charged for new } \\
\text { sexual or non-sexual } \\
\text { offence including } \\
\text { breaches }\end{array}$ & $\begin{array}{l}\text { Circles CM: Any recidivism 28.3\%, sexual 5\%, } \\
\text { violent } 15 \% \\
\text { Non-Circles offenders: Any recidivism } 43.4 \% \text {, } \\
\text { sexual } 16.7 \% \text {, violent } 35 \% \\
\text { In Circles group new offence less severe than } \\
\text { previous offending. }\end{array}$ \\
\hline
\end{tabular}


Table 1. Contd....

\begin{tabular}{|c|c|c|c|c|c|}
\hline Author, Year & Type of Study & Setting & Groups Studied & $\begin{array}{l}\text { Methods and } \\
\text { Outcomes }\end{array}$ & Findings \\
\hline $\begin{array}{l}\text { Bates et al., } \\
\quad 2007\end{array}$ & $\begin{array}{c}\text { Naturalistic } \\
\text { follow-up study }\end{array}$ & $\begin{array}{l}\text { Pilot Circles } \\
\text { project, UK }\end{array}$ & 16 Core Members & $\begin{array}{l}\text { Interviews with } \\
\text { Circles staff and file } \\
\text { reviews }\end{array}$ & $\begin{array}{ll}\text { - } & \text { No sexual reconvictions } \\
\text { - } & \text { One breach of Sex Offence Prevention } \\
\text { Order } \\
\text { - } & 4 \mathrm{CMs} \text { recalled for breaches } \\
\text { - } & 5 \mathrm{CMs} \text { recidivist behaviour }\end{array}$ \\
\hline $\begin{array}{l}\text { Haslewood et } \\
\text { al., } 2008\end{array}$ & $\begin{array}{l}\text { Qualitative } \\
\text { evaluation of } \\
\text { local project }{ }^{1}\end{array}$ & $\begin{array}{c}\text { Circles } \\
\text { project in } \\
\text { Manchester, } \\
\text { UK, which } \\
\text { also provided } \\
\text { advice on } \\
\text { self- } \\
\text { employment }\end{array}$ & $\begin{array}{l}5 \text { Core Members } \\
\text { who had offended } \\
\text { against children (two } \\
\text { intra-familial), high } \\
\text { risk of reoffending } \\
\text { (Matrix 2000), had } \\
\text { undergone sex } \\
\text { offender treatment, } \\
\text { in transition from } \\
\text { hostel to independent } \\
\text { living } \\
11 \text { volunteers } \\
\text { Professionals } \\
\text { working in Circles } \\
\text { Other professionals }\end{array}$ & $\begin{array}{l}\text { In-depth qualitative } \\
\text { interviews with core } \\
\text { members (7), } \\
\text { volunteers (17), } \\
\text { professionals } \\
\text { working in Circles } \\
\text { project (15), other } \\
\text { professionals (9) } \\
\text { Participatory } \\
\text { observation }\end{array}$ & $\begin{array}{l}\text { Core members: } \\
\text { - } \quad \text { Motivation: Have someone to talk to, help } \\
\text { with practical issues and social life } \\
\text { - } \quad \text { Fears: Being judged, confidentiality, might } \\
\text { not work } \\
\text { Volunteers: } \\
\text { - } \quad \text { Motivation: career progression, innovative } \\
\text { approach, make a difference, prevent future } \\
\text { victimisation } \\
\text { - } \quad \text { Fears: impact of offence, being groomed, } \\
\text { not getting on with other volunteers, reac- } \\
\text { tion of others } \\
\text { - } \quad \text { Emphasis on support rather than control } \\
\text { Personal benefits: confidence, experience, } \\
\text { prospects, reward } \\
\text { Project staff: } \\
\text { - } \quad \text { Significant benefits for monitoring behav- } \\
\text { iour } \\
\text { Other professionals: } \\
\text { - } \quad \text { Focus on risk management, concerns about } \\
\text { - } \quad \text { Practical support } \\
\text { Potential benefits for CMs: } \\
\text { Overcoming loneliness, improve social life } \\
\text { Improve coping with stress } \\
\text { lenge and commitment }\end{array}$ \\
\hline $\begin{array}{l}\text { Wilson et al., } \\
2009\end{array}$ & $\begin{array}{l}\text { Controlled trial } \\
\text { with matched } \\
\text { control group, } \\
\text { not randomised }\end{array}$ & $\begin{array}{c}\text { Canadian } \\
\text { Circles }\end{array}$ & $\begin{array}{l}44 \text { Core Members, } \\
\text { high risk } \\
44 \text { controls matched } \\
\text { on risk, time in } \\
\text { community, location } \\
\text { and treatment history }\end{array}$ & $\begin{array}{l}\text { Charged for or } \\
\text { convicted of new } \\
\text { sexual and non- } \\
\text { sexual offence }\end{array}$ & $\begin{array}{l}\text { Circles CM: Any recidivism } 11.4 \% \text {, sexual } 2.3 \% \text {, } \\
\text { violent } 9.1 \% \\
\text { Non-Circles offenders: Any recidivism } 38.6 \% \text {, } \\
\text { sexual } 13.7 \% \text {, violent } 34.1 \%\end{array}$ \\
\hline
\end{tabular}

more fear about the communities' reaction towards them compared to their British counterparts and hoped the Circle would protect them. Although prevention of re-offending did not appear to be a specific motivation for offenders to join a Circle in the studies reviewed, a large majority of CM identified such an effect and felt they had re-offended were they not part of a Circle.

${ }^{1}$ Only findings relevant to outcomes of offenders, impact on volunteers or stakeholders are reported here; not reported are findings regarding the setting up of Circles and their operation.

\section{Volunteers'Perspectives}

We identified three studies interviewing volunteers on their motivation to become involved in a Circles project and on their perceived benefit of the Circle to stakeholders (Cesaroni, 2001; Haslewood-Pócsik, Smith \& Spencer, 2008; Wilson, Picheca, \& Prinzo, 2007a). Volunteers appear to be mainly motivated by wanting to help a sex offender to reintegrate into the community; increased community safety was another common theme. While sex offenders seem 
unlikely recipients of benevolent acts by ordinary community members, it is of note that the studies reviewed found that a large proportion of volunteers had worked with offenders before and a significant minority had personal experience with victimisation in their own families. Volunteers reported positive effects of their involvement on their own lives beyond the satisfaction derived from successfully supporting a sex offender, e.g. regarding their professional development, confidence and social interactions. Sadly, nevertheless volunteers often reported not being able to disclose their involvement with Circles to their friends or even family. Similarly to CMs, volunteers felt Circles had made a difference to the safety of communities in that it prevented re-offending even though more experienced volunteers were somewhat less optimistic about the impact of Circles (Wilson, Picheca, \& Prinzo, 2007a).

\section{Other Stakeholders' Perspectives}

Two of the studies looking at the experience of CMs and volunteers also identified the views of professionals, both those directly involved in Circles and those more removed from their operation (Haslewood-Pócsik, Smith \& Spencer, 2008; Wilson, Picheca, \& Prinzo, 2007a). As might be expected, professionals more closely involved in Circles projects expressed more positive views about Circles and their potential impact on outcomes in sex offenders. Other professionals were more reserved and emphasized the role of Circles for surveillance purposes over their supportive role. A minority of stakeholders in one study (Wilson, Picheca, \& Prinzo, 2007a) felt there were potential issues regarding boundaries and a lack of structure in Circles and that more training for volunteers would be desirable. Hazlewood et al. (Haslewood-Pócsik, Smith \& Spencer, 2008) also reported that project staff had expressed concerns over the exchange of phone numbers between the $\mathrm{CM}$ and volunteers in one Circle. However, most professionals appreciated this additional resource of support and the positive effects for reintegration of sex offenders. Only one study investigated perceptions of members of the community-at-large (Wilson, Picheca, \& Prinzo, 2007a). The authors reported a mainly positive view on Circles by community members with only a small proportion expressing resentment about the offenders receiving help. Nearly three quarters of members of the community felt that Circles would make their communities safer.

\section{Effectiveness of Circles}

The earliest Canadian practice of Circles was evaluated in research that compared a group of sex offenders involved with Circles with a comparison group who were not (Wilson, Picheca \& Prinzo, 2005). The groups were matched on actuarial risk assessment ratings (STATIC-99), time in community and prior exposure to treatment interventions. They were followed up for an average of 4.5 years. Sexual, violent and general reconviction rates for the men involved with Circles were lower than for the comparison group - most notably in the sexual reconviction category where individuals in the Circles group were reconvicted at half the rate of the comparison group (8.3\% as opposed to $16.7 \%$ ) despite a slightly (not statistically significant) higher average risk assessment rating on STATIC-99 (average 5.6, SD 2.22, as opposed to 5.0, SD2 ) and significantly higher scores on the RRASOR (average 3.18, SD 1.65 versus 2.12, SD 1.31). The rate of sexual reconviction was just over a quarter of the calculated expected rate ( $8.3 \%$ rather than $28.5 \%$ expected) as opposed to the comparison group where it was well over half the expected rate $(16.7 \%$ rather than $26.5 \%)$. This outcome showed that, while no complete panacea, the impact of Circles reduced the sexual reconviction rate of high-risk offenders to a statistically significant degree $(p<0.01)$. In this case, 'high risk' was indicated in both experimental and control groups because all cases had been detained until their Warrant Expiry Date (WED), which is only recommended in cases where re-offense is likely to occur prior to WED (McAlinden, 2007).

Subsequent Canadian research (Wilson, Cortoni, Meunier \& Vermani, 2006; Wilson, Cortoni \& McWhinnie, 2009). replicated these findings. This research identified reconviction rates of Circles participants from across Canada once the model had been more extensively implemented. Forty-four cases in each category (Circles and a matched control group) were followed up for, on average, a little under three years. In this study Circles Core Members had slightly higher scores on the STATIC-99 but not on other risk assessment tools employed. Sexual recidivism was only $2.3 \%$ in the Circles group but $13.7 \%$ in the control group. Violent reconviction rates were also much lower for the Circles group $(9.1 \%$ as opposed to $34.0 \%)$. The total number of convictions and charges of any kind (arguably a more meaningful figure given the complications inherent in securing a sexual conviction) was far lower in the Circles sample - 17 rather than 73 in the control group, again a highly statistically significant difference $(\mathrm{p}<0.01)$. Although a shorter follow-up period than Wilson et al.'s 2005 research this latter evidence again shows a very positive finding for the activities of COSA in rehabilitating high-risk sex offenders and thereby making communities safer.

Research in the UK (Bates, Saunders \& Wilson, 2007) until now has focused on a more qualitative approach. A group of 16 core members involved with what was then the Thames Valley Circles were followed up for an average of 2.2 years. No control group was available for analysis although the research followed-up each of the 16 cases in detail, noting not only further convictions but any other 'recidivist' behaviours (e.g. other problematic behaviours which fall short of illegality and reconviction). This gave a wider perspective on the functioning of the Core Members and the ways in which Circles impacted upon their lives. In this study there were no sexual reconvictions. The study sought to establish in more detail how this positive overall outcome came about. It incorporated 'soft data' which were available on a CM's behaviour from Circles records. Any instance of pro-offending, offence-paralleling or otherwise problematic behaviour was recorded routinely in the CM's file.

Regarding the findings of this study one CM was convicted for breach of a Sex Offence Prevention order (a civil order imposed upon him by a court as a result of his evidenced and ongoing high level of risk of reconviction). Four further CMs were recalled to prison on licence and in these cases the high level of risk presented by this group may be born out by the incidences of their recidivistic behaviours 
which gave rise to sufficient concern that they were recalled to prison. However, it should be noted that due to such evasive action, which in many cases was prompted specifically by the input of Circles, sexual reconvictions and the creation of further victims were avoided. For example, in the case of one CM the Circle received information that he had secretly purchased a car, which had been part of his modus operandi for his previous sexual offence of abduction of a child. The offender had used the car to travel to visit a previous associate involved with him in grooming of children. Circle volunteers reported this to the police Public Protection Officer and subsequently a Circle Coordinator and volunteers visited the CM when children and two girls aged 6 and 14 were found in his flat. This resulted in the CM being prosecuted for breach of his SOPO (Sexual Offences Prevention Order), although he remained in the Circle subsequently. In another case a CM informed a Circles volunteer that he had met with female child and drunk alcohol with her. The volunteer informed the police and probation of this matter but supported $\mathrm{CM}$ through this process, which led to recall. Such activity by Circles volunteers illustrates the 'Accountability' aspect of the Circles process which at times, might be viewed as sitting uneasily alongside the 'Support' element. However, in the HTV study (Ward \& Gannon, 2006) the fact that four CMs that were subject to breach proceedings (of SOPO or licence) then returned to the Circle for ongoing support and accountability demonstrates how it is possible for these two key aspects of Circles practice to co-exist

\section{DISCUSSION}

\section{Qualitative Research on Circles}

There is a limited but growing qualitative research literature identifying mainly positive experiences with Circles across a range of stakeholders. While this literature has identified some initial reservations and concerns by professionals in the criminal justice system, this might be due to the relatively recent introduction of Circles and associated uncertainties regarding best practice. There was no support in the literature reviewed here for major concerns regarding the motivations and quality of volunteers recruited to Circles project. Some concerns were expressed by some professionals regarding potential boundary violations although there was no evidence to suggest that this had caused any problems in practice. It was of note that one study (Cesaroni, 2001) reported own experience with abuse as one of the reasons for volunteers to become involved. Although this is not further discussed in their study, projects need to be aware of this group of volunteers as they might be particularly vulnerable to experience distress during their involvement, e.g. through post-traumatic memories. Projects need to be aware of this possibility and provide adequate support for volunteers affected by their experience in the Circle. The evidence available suggests that volunteers are predominantly mature professionals, motivated by a desire to help, but without being naive about risks and possible achievements. It was particularly striking to note the mainly positive response from individuals from the general public in one study (Wilson, Picheca \& Prinzo, 2007a) which appeared surprising given the very negative response sex offenders receive when released into the community. It is possible that education contributes to change people's views from largely negative and rejecting to a more measured ap- proach. This proposition is supported by the observation by Wilson (Wilson, Picheca \& Prinzo, 2005) who reported that nearly half of the members of the general public they interviewed were aware of Circles and what it offers to offenders through publicity prior to setting up new projects. While such qualitative research can ultimately not prove that Circles 'work' it may in the future help to identify the factors that might be useful in the success or otherwise of Circles and can thereby inform best practice.

\section{Quantitative Research on Circles}

Whereas Core Members, Circles professionals and other stakeholders, including members of the community, all expressed the view that Circles had helped to reintegrate offenders into the community, reduce their re-offending and make communities safer, such 'soft data' has to be supported by scientific evidence, ideally in controlled studies. So far, only three studies, two in Canada and one in the UK, have evaluated the impact of Circles on outcomes for high risk sex offenders; two of these studies included a control group. These studies reported encouraging findings in reasonably sized carefully matched samples of high risk offenders although interventions were not randomly allocated. Unfortunately the authors did not describe eligibility criteria for Circles and therefore one cannot rule out some bias on the basis of motivation to participate in a Circle. Such concerns could ultimately only be addressed in a randomized controlled trial which would pose significant ethical concerns as outlined below.

\section{Directions for Future Research}

At the time of writing there have been no further published evaluations of Circles in the UK following Bates et al. (Bates, Saunders \& Wilson, 2007). This is a high priority for future research, given the expansion of the initiative, in order to demonstrate value-for-money for government and charitable funders. Studies evaluating follow-up behaviour of CMs are important, preferably with matched control groups and yet retaining a wider perspective than simply looking at reconviction rates. These are now widely regarded in the field of forensic research as something of a 'blunt instrument' in establishing if and how offenders are successfully rehabilitated into society (Friendship, Thornton, Erikson \& Beech, 2001) given low rates of reporting, prosecution and conviction of sex offences.

A variety of evaluative approaches are being considered under the auspices of a Research and Evaluation Group established by Circles UK. This group consists of academics and practitioners with backgrounds in law, criminology and forensic psychology and psychiatry. Charitable funding has been accessed to pay for a full-time Doctoral researcher to carry out an evaluation of Circles in the UK. The options for evaluation are varied and all have advantages and disadvantages attached to them.

\section{Reconviction Studies}

Such studies use statistics available from the Police National Computer and other sources to identify the future reconvictions of sex offenders. Over the longer term Circles will need to identify if reconviction rates for core members differ from a matched sample of sex offenders who have not received a Circles intervention. Ideally this would involve 
identifying a control group which includes sex offenders as closely matched as possible (in particular in terms of risk assessment) with the Circles group. The simplest way to create such a group is to allocate half of all sex offenders found suitable for a Circle to the active intervention and half to 'treatment as usual'. However, there are significant ethical issues here because offenders would be denied a service which might prevent them from committing further offences which will cause harm and distress not only to them but crucially to potential victims who are inherently unidentifiable and cannot consent to this practice. However, there is a precedent here in the evaluation of a Restorative Justice initiative run by the Justice Research Consortium across three sites in the UK from 2001 (Shapland, Atkinson, Atkinson, Dignan, Edwards, et al., 2008). This used an experimental model in which cases were randomly allocated to either a restorative justice conference or a control group after victim and offender consent for the intervention had been obtained and thereby the evaluation was able to control for the crucial factor of motivation to engage in the intervention. It may be that there will come a time for Circles projects that there are too many applicants for Circles for them all to receive the intervention, in which case the control group would create itself naturally by consisting of those offenders who simply did not receive an intervention due to shortage of resources. However, in the largest and most widely operating Circles UK project (in Thames Valley and Hampshire - HTV) this eventuality has yet to come about because, in order to ensure they provide as wide a service as possible to maintain continued support from public agency funders, HTV Circles have sought to diversify the interventions they provide (for example, offering a counselling and monitoring service alongside actual Circles). In practice this means that almost all sex offenders identified as suitable for some kind of Circles intervention have received it. This may change when the numbers of referrals increase still further and the role and scope of the project becomes defined more clearly, perhaps by the provision of longer-term funding which will allow the project to focus on its particular designated interventions rather than shifting its practice for reasons described above.

The alternatives for control groups are more complicated to arrange although can include a retrospective control group drawn from a sample of sex offenders identified from probation records who received a sex offender treatment programme but not Circles. They would need to be matched as closely as possible for risk assessment but this would still not control for motivation e.g. any more positive outcome for Core Members might just relate to their higher level of motivation for volunteering and being found suitable for Circles in the first place.

In undertaking any follow-up study it will be crucial to define precisely what a 'negative outcome' for a $\mathrm{CM}$ is, as failing to do so could give misleading results. In the Canadian research, for instance, a breach of parole licence and return to prison was deemed a failed outcome (Wilson, Picheca, \& Prinzo, 2007b). In the existing HTV Circles research (Bates, Saunders, \& Wilson, 2007) the sample were breached at a rate of $25 \%$. There was no comparison data here for a non-Circles control group but it may well be that the breach rate would not be this high in those sex offenders who received treatment alone as they would be less monitored and controlled than the Circles sample. The research identified how the Circles activity had actually contributed towards the breach action (under the Accountability aspect of its function). It could be argued that only reconviction (or strong recidivism evidence) of a further sexual offence should count as a failed outcome.

\section{Psychometric Evaluation}

Psychometric tests are used in an evaluative capacity in many offending-behaviour interventions run in the prison and probation services in the UK. They can provide evidence of attitudinal change in offenders who have undertaken treatment programmes which may then translate to behavioural change in the longer term although the evidence for their use in sex offender populations, particularly as a measure of change, is limited. Nevertheless, psychometric testing could be considered as an evaluation approach within Circles although identifying which psychometric tests might best measure the attitudes and personality characteristics which are being targeted by Circles interventions is challenging. One suggestion (Barker, 2009) has been to use psychometric questionnaires to measure the capacity to achieve psychological 'goods' which are a feature of the Good Lives Model (Ward \& Gannon, 2006). This theory essentially suggests that sex offenders offend in order to meet primary human needs and if these needs could be met in legal, non-abusive ways then this would reduce their desire to offend. Circles fits into the Good Lives model in that Circles provide aspects of human communication, support and advice which can be interpreted as 'goods' in the Good Lives Model.

\section{Dynamic Risk Factors Review}

Another relevant area for developing evaluation methods applied to Circles would be to focus on the dynamic, i.e. changeable, risk factors identified in the sex offender literature (Losel \& Schmucker, 2005) through the course of a Circle and beyond. To this end, practitioners and researchers working within Circles UK have designed a document to be completed by a Circle at regular intervals which specifically identifies dynamic risk factors identified in the sex offender treatment literature and how they might relate to the CM during their involvement in a Circle. The document is intended to be brief and user-friendly so that it may be utilised requiring the minimum amount of volunteers' time while still providing vital information over time in a consistent manner across different Circles. It allows for detailed, ongoing monitoring of the $\mathrm{CM}$ based upon factors identified as relevant to their risks of reoffending. Circles UK have made provisions to systematically collate and feedback information recorded in this way to local projects in order to provide evidence of progress or, conversely, identify risk issues relating to each CM.

\section{CONCLUSIONS}

This paper provides a summary of the COSA initiative thus far, from its origins in Canada through developments in UK policy and practice at a local and national level. COSA represents a community-based response to a community problem which gives a practical alternative to the often unhelpful demonising approach to sexual abuse prevalent in much of the media. Existing evaluative studies of COSA practice in Canada and the UK have been outlined but further research is required in order to more thoroughly 
examine the impact of COSA in the management of sex offenders in the community, and in particular the factor contributing to positive or negative outcome. In addition to this, research would be useful regarding how and why members of the public volunteer for COSA and what benefits (both personal and professional) they may gain from this process. Also, it would be useful to examine how the activities of COSA might be demonstrated to impact more generally on community awareness and safety when considering the risk of serious harm to children and vulnerable adults which sexual abuse represents.

\section{CONFLICT OF INTEREST}

$\mathrm{CW}$ is national development officer for Circles UK.

$\mathrm{AB}$ is a forensic psychologist employed by Thames Valley Probation Service, and seconded to HTV Circles and Circles UK for 20 days a year.

$\mathrm{BV}$ is a trustee of Circles UK.

\section{REFERENCES}

Barker, J. (2009). The application of the good lives model to COSA. Unpublished Forensic Psychology MSc dissertation. Leicester University.

Bates, A., Saunders, R., Wilson, C. (2007). Doing something about it: a follow-up study of sex offenders participating in Thames valley Circles of Support and Accountability. British Journal of Community Justice 5, 19-42.

Cesaroni C. (2001). Releasing sex offenders into the community through "Circles of Support" - a means of reintegrating the "Worst of the Worst". Journal of Offender Rehabilitation 34, 85-98.

Friendship, C., Thornton, D., Erikson, M., Beech, A. (2001). Reconviction: a critique and comparison of two main data sources in England and Wales. Legal and Criminological Psychology 6, 121-129.

Hanson, R.K. \& Morton-Bourgon, K. (2005). Predictors of sexual recidivism: an updated meta-analysis. Ottawa, Canada: Corrections Research, Public Safety and Emergency Preparedness.
Haslewood-Pócsik, I., Smith, E., Spencer, J. (2008). IMPACT Circles: balancing risk management with support. Manchester: Criminal Justice Unit, University of Manchester.

Losel, F. \& Schmucker, M. (2005). The effectiveness of treatment for sexual offenders: a comprehensive meta-analysis. Journal of Experimental Criminology 1, 117-146.

Mann, R. \& Shingler, J. (2006). Collaboration in clinical work with sex offenders: Treatment and risk assessment. In Marshall, W.L., Fernandez, Y.M., Marshall, L.E., Serran, G.A. (Eds). Sexual offender treatment: controversial issues. Chichester, UK: John Wiley and Sons.

McAlinden, A. (2007). The Shaming of Sexual Offenders: Risk, Retribution and Reintegration. Oxford, UK: Hart Publishing.

Saunders, R. \& Wilson, C. (2003). Three key principles: a theoretical framework. Circles of Support and Accountability in the Thames Valley: an interim report. London, UK: Quaker Peace and Social Witness.

Shapland, J., Atkinson, A., Atkinson, H., Dignan, J., Edwards, L. et al. (2008). Does restorative justice affect reconviction? The fourth report from the evaluation of three schemes. Ministry of Justice Research Series 10/08. London: Ministry of Justice.

Ward, T., Gannon, T.A. (2006). Rehabilitation, etiology and self-regulation: the comprehensive good lives model of treatment for sexual offenders. Aggression and Violent Behaviour 11, 77-94.

Wilson, R.J., Picheca, J., Prinzo, M. (2005). Circles of Support \& Accountability: An evaluation of the pilot project in South-Central Ontario. Ottawa, Canada: Correctional Service of Canada.

Wilson, R., Cortoni, F., Meunier, R., Vermani, M. (2006). Support and Accountability: a national replication of outcome findings. ATSA conference presentation.

Wilson, R., Picheca, J., Prinzo, M. (2007a). Evaluating the effectiveness of professionally-facilitated volunteerism in the community based management of high risk sexual offenders: part one - effects on participants and stakeholders. The Howard Journal 46, 289-302.

Wilson, R.J., Picheca, J., Prinzo, M. (2007b). Evaluating the effectiveness of professionally-facilitated volunteerism in the community based management of high risk sexual offenders: part two - a comparison of recidivism rates. The Howard Journal 46, 327-337.

Wilson, R.J., Cortoni, F., McWhinnie, A.J. (2009). Circles of Support \& Accountability: A Canadian National Replication of Outcome Findings. Sexual Abuse: A Journal of Research and Treatment 21, $412-430$.

(C) Wilson et al.; Licensee Bentham Open.

This is an open access article licensed under the terms of the Creative Commons Attribution Non-Commercial License (http://creativecommons.org/licenses/by-nc/3.0/) which permits unrestricted, non-commercial use, distribution and reproduction in any medium, provided the work is properly cited. 